\title{
The Factors Affecting Survival in Geriatric Hemodialysis Patients
}

\author{
Murat Tuğcu (iD, ${ }^{1}$ Umut Kasapoğlu, ${ }^{2}$ Gülizar Şahin, ${ }^{3}$ and Süheyla Apaydın ${ }^{4}$ \\ ${ }^{1}$ Department of Nephrology, Marmara University Pendik Training and Research Hospital, Istanbul, Turkey \\ ${ }^{2}$ Department of Nephrology, A $\breve{g r}$ Public Hospital, Ağrl, Turkey \\ ${ }^{3}$ Department of Nephrology, Sultan Abdulhamid Han Training and Research Hospital, Istanbul, Turkey \\ ${ }^{4}$ Department of Nephrology, Bakirkoy Sadi Konuk Training and Research Hospital, Istanbul, Turkey
}

Correspondence should be addressed to Murat Tuğcu; drmrttgc@hotmail.com

Received 18 December 2017; Revised 27 May 2018; Accepted 21 June 2018; Published 10 July 2018

Academic Editor: Suresh C. Tiwari

Copyright (C) 2018 Murat Tuğcu et al. This is an open access article distributed under the Creative Commons Attribution License, which permits unrestricted use, distribution, and reproduction in any medium, provided the original work is properly cited.

\begin{abstract}
Introduction. The number of geriatric patients is increasing in hemodialysis population over the years and mortality is higher in this group of patients. This study evaluated the factors affecting geriatric hemodialysis patient survival. Materials and Methods. This retrospective cohort study enrolled patients discharged from our nephrology clinic from 2009 to 2014. Data collected included demographics, Eastern Cooperative Oncology Group-Performance Status, vascular access type, and metabolic parameters. Comorbidity was quantified using the modified Liu comorbidity index. The outcome measure was mortality. Results. The study enrolled 99 elderly dialysis patients $(42.4 \%$ women $(n=42)$; mean age $75 \pm 7$ years). The mean follow-up duration was $19.7 \pm 11$ months. The mortality rate over the four years was $47.5 \%(n=46)$. The modified Liu comorbidity index score, patient age, and Eastern Cooperative Oncology Group-Performance Status were significantly related to mortality in univariate and multivariate analyses. Conclusion. The present study revealed that comorbidities and low performance status at the onset of dialysis had shortened the survival time in the geriatric hemodialysis patient group.
\end{abstract}

\section{Introduction}

The elderly dialysis population has grown with the increase in the number of elderly people in many countries [1]. However, treatment decisions are difficult because the older dialysis population has a high burden of chronic health conditions and their limited life expectancy [2]. Several comorbidity index scoring systems have also been used to evaluate the prognosis of these patients objectively [3-6]. And, also, performance status generally reflects comorbidity burden and has prognostic significance, especially chronic diseases such as chronic kidney disease.

In fact, no established guidelines exist to inform the practice of hemodialysis in the elderly population. And also hemodialysis practice in elderly patients was different and tended to follow region-specific practices. This study is one of the few studies in this field in Turkey and evaluated the relationship between the Eastern Cooperative Oncology
Group-Performance Status (ECOG-PS) and modified Liu comorbidity index (mLCI) score in survival in a geriatric hemodialysis population. We hypothesized that there would be negative correlations between comorbid diseases and performance status and survival outcome.

\section{Materials and Methods}

Geriatric dialysis patients (age $>65$ years) who were started on hemodialysis between January 1, 2011, and December 31, 2014, at our nephrology clinic were analyzed retrospectively. Maintenance hemodialysis was defined as undergoing dialysis for more than 90 days and patients who died or switched from hemodialysis to peritoneal dialysis or transplanted were excluded. The hemodialysis is performed at the different private dialysis centers three times per week. The patients were followed from the first reported hemodialysis date to the date of death or December 31, 2014. 
TABle 1: Liu Comorbidity Index, 11 comorbid conditions, and weighing score.

\begin{tabular}{lc}
\hline Comorbid Conditions & Weighing Score \\
\hline Diabetic Mellitus & 1 \\
\hline Coronary Artery Disease & 3 \\
\hline Congestive Heart Disease & 1 \\
\hline Cerebrovascular Disease & 2 \\
\hline Peripheral Vascular Disease & 2 \\
\hline Other Cardiac & 2 \\
\hline Dysrhythmia & 2 \\
\hline Chronic Obstructive Pulmonary Disease & 2 \\
\hline Gastrointestinal Bleeding & 2 \\
\hline Liver Disease & 2 \\
\hline Cancer & 2
\end{tabular}

Patient demographic data, comorbidities, and date of death information were obtained from the National Dialysis Management System and computerized hospital records. Baseline metabolic parameters were taken at the 3rd month after starting of hemodialysis. Patient general health status before initiating dialysis was graded according to the ECOGPS, ranging from 0 to 5 , with 0 indicating that the patient is active and capable of normal everyday activity and 5 indicating that he or she is dead [7].

We calculated the mLCI (we allowed claims-based diagnosis capture to commence immediately upon initiating dialysis for a 90-day period). Briefly, this index assigns the following weights for 11 conditions: 1 point for atherosclerotic heart disease and diabetes; 2 points for cerebrovascular accident/transient ischemic attack, peripheral vascular disease, dysrhythmia, other cardiac diseases, chronic obstructive pulmonary disease, gastrointestinal bleeding, liver disease, and cancer; and 3 points for congestive heart failure (Table 1).

The data were analyzed using the Statistical Package for the Social Sciences for Windows 20.0 (SPSS, Chicago, IL, USA). Study subjects were censored if they were alive until December 31, 2014. The primary outcome (event) was death from any cause. Numeric data were presented as mean \pm standard deviation. Either the Student's $t$-test or the Mann-Whitney U test was used for comparing the two groups. In univariate and multivariate analyses, mortality was the dependent variable and other variables were independent variables. We used the method of subtracting the mean to remove the multicollinearity produced by interaction of variables. Significance was set at $P<0.05$.

\section{Results}

This study enrolled 99 elderly dialysis patients with a mean age of $75 \pm 7$ years; $42.4 \%$ were women $(n=42)$. The mean duration of follow-up was $19.7 \pm 11$ months. During the fouryear study period, 47 (47.5\%) patients died. Although most patients $(68.7 \%)$ had chronic renal failure before initiating dialysis, a temporary hemodialysis catheter was the main vascular access (87.9\%). Baseline metabolic parameters, primary

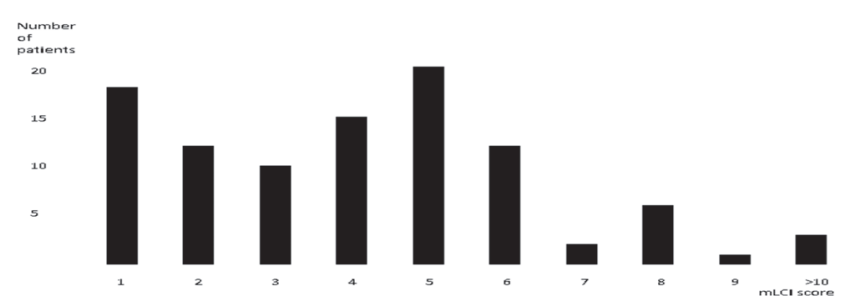

FIGURE 1: Distribution of mLCI score according to number of patients.

renal disease, vascular access type, and gender did not differ significantly between survivors and nonsurvivors (Table 2).

Chronic comorbidities were very common in the nonsurvivors; the mean mLCI was $3,7 \pm 2,3$, and also the mean age (77.4 \pm 7.80 years) and ECOG-PS $(2.8 \pm 1)$ were higher in this group. In the univariate and multivariate model, age, ECOG-PS, and mLCI score were significantly associated with mortality (Table 3).

The mLCI score distribution is shown in Figure 1. Patients with low mLCI score had a significantly better survival rate than those with a high mLCI score $(p=0.027)$. Older age group were significantly associated with mortality $(p=0.047)$.

\section{Discussion}

Approximately one-third of elderly patients with end-stage renal disease (ESRD) have four or more chronic health conditions and most are not candidates for kidney transplantation [2]. When geriatric patients need dialysis, treatment decisions based on the patient's underlying condition and probable outcome are difficult $[8,9]$.

Mortality in elderly patients is closely correlated with many comorbidities independent of age $[10,11]$. Therefore, multiple scoring systems have been developed and more than 80 randomized trials have been published to help physicians assess whether a dialysis patient could benefit from therapy and have their lifespan prolonged [12-15].

Liu et al. developed an improved comorbidity index for dialysis patients, the Liu comorbidity index (LCI) [16], which covers comorbid conditions, but not age, which is already a strong predictor of mortality. Recently, Rigler et al. modified the Liu comorbidity index because of the 270-day survival requirement for patient selection. Consequently, they could include sicker patients more prone to early mortality and reduce sample size loss without survivor bias. They found that the mLCI was as effective as the original [17].

Because mortality may be high in the first few months after initiating dialysis therapy, especially for elderly patients [1], we used mLCI for scoring our patients comorbidities and found that patients with higher mLCI scores had a shorter life expectancy $(p=0.009)$. Similar to our results, Khan et al. also found that patients in the highest LCI score group had the highest mortality risk and lowest survival rate [18].

Multiple comorbidities limit physical functioning; performance status is a vital instrument because it significantly influences morbidity and mortality [19]. Clinicians worldwide consider the ECOG-PS when planning new treatments 
TABLE 2: Univariate analysis of clinical and metabolic parameters (at the 3rd month after starting hemodialysis). Significance was set at $\mathrm{P}<$ 0.05 .

\begin{tabular}{|c|c|c|c|}
\hline Variables & $\begin{array}{l}\text { SURVIVORS } \\
\text { N: } 52\end{array}$ & $\begin{array}{c}\text { NON- } \\
\text { SURVIVORS N: } \\
47\end{array}$ & $P$ \\
\hline Age & $73 \pm 6$ & $77.4 \pm 7.80$ & 0,012 \\
\hline Gender, Women (\%) & 39 & 47 & 0,545 \\
\hline mLCI score & $2,5 \pm 2,2$ & $3,7 \pm 2,3$ & 0,009 \\
\hline ECOG-PS & $2.3 \pm 0.8$ & $2.8 \pm 1$ & 0,023 \\
\hline Temporary Vascular Access (\%) & 87 & 89 & 0,722 \\
\hline $\begin{array}{l}\text { Ischemic / Atherosclerotic (Primary Kidney } \\
\text { Diseases) }\end{array}$ & 8 & 11 & 0,255 \\
\hline $\begin{array}{l}\text { Interstitial Nephritis (Acute / Chronic) } \\
\text { (Primary Kidney Diseases) }\end{array}$ & 4 & 3 & 0,476 \\
\hline Diabetic mellitus (Primary Kidney Diseases) & 16 & 12 & 0,149 \\
\hline $\begin{array}{l}\text { Unknown Etiology (Primary Kidney } \\
\text { Diseases) }\end{array}$ & 10 & 17 & 0,24 \\
\hline Other (Primary Kidney Diseases) & 8 & 8 & 0,65 \\
\hline Serum Creatinine $(\mathrm{mg} / \mathrm{dl})$ & $7 \pm 3$ & $6.1 \pm 2.4$ & 0,11 \\
\hline Serum Albumin ( $g r / d l)$ & $2.7 \pm 0.5$ & $2.6 \pm 0.6$ & 0,232 \\
\hline Venous Bicarbonate $(\mathrm{mmol} / \mathrm{L})$ & $16.6 \pm 6$ & $17.3 \pm 5.2$ & 0,72 \\
\hline Hemoglobin $(\mathrm{g} / \mathrm{dl})$ & $8.7 \pm 1.3$ & $9.2 \pm 1.3$ & 0,74 \\
\hline C-Reactive Protein (mg/dl) & $5.1 \pm 5.7$ & $6 \pm 7$ & 0,77 \\
\hline Ferritin $(\mathrm{ng} / \mathrm{ml})$ & $400 \pm 336$ & $836 \pm 1855$ & 0,10 \\
\hline Proteinuria (g/day) & $3.2 \pm 3$ & $2.6 \pm 2.5$ & 0,36 \\
\hline Cardiac Ejection Fraction (\%) & 51 & 49 & 0,85 \\
\hline
\end{tabular}

TABLE 3: Multivariate analysis of clinical and metabolic parameters. All variables in Table 2 were included in multivariate analysis, but only statistically significant results are presented in Table 3. Significance was set at $P<0.05$.

\begin{tabular}{lccr}
\hline Dependent Variable & \multicolumn{3}{c}{ Multivariate Analysis } \\
\hline Age & Odds ratio & \%95 CI & P value \\
\hline mLCI score & 5,520 & $1,8-18,1$ & 0,021 \\
\hline ECOG-PS & 4,944 & $1,6-12,2$ & 0,029 \\
\hline
\end{tabular}

for elderly patients [20]. We found that the ECOG-PS was related to mortality. Similar to our results, in a Japanese study, ECOG-PS was a prognostic factor in a multivariate analysis of hemodialysis patients aged $\geq 80$ years [9]. However, we could not find a significant linear correlation between the mLCI score and ECOG-PS. However, the addition of functional status/fragility can help develop comorbidity scoring systems [21].

Age is a strong independent predictor in all existing scoring systems and we also found that older age was related to higher mortality. Another recent study found that dialysis may not benefit the survival of patients over 75 years old who have multiple comorbidities [22]. Nevertheless, older age should not be an obstacle to dialysis treatment because patients with a low mLCI may have an acceptable mean life expectancy.

This study has several important limitations. The number of subjects was small and we did not classify the severity of each comorbid condition. However, we recorded the ECOG-PS and it may indirectly quantify the severity of all comorbidities. And, also, the study was retrospective and the patients included were from a single institution.

\section{Conclusion}

Treatment of ESRD in geriatric population is complex and there is a lot of questions on how to best manage these patients. Our study evaluated the life expectancy of geriatric hemodialysis patients using mLCI score, age, and ECOGPS. Our findings may help suggesting the prognosis of geriatric patients after starting dialysis and mortality is high in geriatric hemodialysis patients who have many comorbidities (i.e., higher mLCI scores), especially those with poor daily living status (i.e., higher ECOG-PS) and our findings contribute to international clinical experience.

\section{Conflicts of Interest}

The authors declare that they have no conflicts of interest. 


\section{References}

[1] A. J. Collins, R. N. Foley, and B. Chavers, "United States Renal Data System 2011 Annual Data Report: atlas of chronic kidney disease \& end-stage renal disease in the United States," American Journal of Kidney Diseases, vol. 59, no. 1, supplement 1, p. A7, 2012.

[2] J. W. Chae, C. S. Song, H. Kim, K. B. Lee, B. S. Seo, and etal., "Prediction of mortality in patients undergoing maintenance hemodialysis by Charlson Comorbidity Index using ICD," Nephron Clinical Practice, vol. 117, no. 4, pp. c379-c384, 2011.

[3] N. V. Athienites, D. C. Miskulin, G. Fernandez et al., "Comorbidity assessment in hemodialysis and peritoneal dialysis using the index of coexistent disease," Seminars in Dialysis, vol. 13, no. 5, pp. 320-326, 2000.

[4] M. Kurella, K. E. Covinsky, A. J. Collins, and G. M. Chertow, "Octogenarians and nonagenarians starting dialysis in the United States," Annals of Internal Medicine, vol. 146, no. 3, pp. 177-183, 2007.

[5] R. Werb, "Palliative Care in the Treatment of End-Stage Renal Failure," Primary Care-Clinics in Office Practice, vol. 38, no. 2, pp. 299-309, 2011.

[6] M. E. Charlson, P. Pompei, K. L. Ales, and C. R. MacKenzie, "A new method of classifying prognostic comorbidity in longitudinal studies: development and validation," Journal of Chronic Diseases, vol. 40, no. 5, pp. 373-383, 1987.

[7] M. M. Oken, R. H. Creech, and D. C. Tormey, "Toxicity and response criteria of the Eastern Cooperative Oncology Group," American Journal of Clinical Oncology, vol. 5, no. 6, pp. 649-655, 1982.

[8] F. E. M. Murtagh, J. E. Marsh, P. Donohoe, N. J. Ekbal, N. S. Sheerin, and F. E. Harris, "Dialysis or not? A comparative survival study of patients over 75 years with chronic kidney disease stage 5," Nephrology Dialysis Transplantation, vol. 22, no. 7, pp. 1955-1962, 2007.

[9] A. Burns, "Conservative management of end-stage renal failure: masterly inactivity or benign neglect? See Smith et al., pp. c40c46.", Nephron Clinical Practice, vol. 95, no. 2, pp. c37-39, 2003.

[10] D. Joly, D. Anglicheau, C. Alberti et al., "Octogenarians reaching end-stage renal disease: cohort study of decision-making and clinical outcomes," Journal of the American Society of Nephrology, vol. 14, no. 4, pp. 1012-1021, 2003.

[11] D. L. Lamping, N. Constantinovici, P. Roderick et al., "Clinical outcomes, quality of life, and costs in the North Thames dialysis study of elderly people on dialysis: a prospective cohort study," The Lancet, vol. 356, no. 9241, pp. 1543-1550, 2000.

[12] J. G. Van Manen, J. C. Korevaar, F. W. Dekker, E. W. Boeschoten, P. M. M. Bossuyt, and R. T. Krediet, "How to adjust for comorbidity in survival studies in ESRD patients: A comparison of different indices," American Journal of Kidney Diseases, vol. 40, no. 1, pp. 82-89, 2002.

[13] L. Fried, J. Bernardini, and B. Piraino, "Charlson comorbidity index as a predictor of outcomes in incident peritoneal dialysis patients," American Journal of Kidney Diseases, vol. 37, no. 2, pp. 337-342, 2001.

[14] B. Di Iorio, N. Cillo, M. Cirillo, and N. Gaspare De Santo, "Charlson Comorbidity Index is a predictor of outcomes in incident hemodialysis patients and correlates with phase angle and hospitalization," The International Journal of Artificial Organs, vol. 27, no. 4, pp. 330-336, 2004.

[15] D. C. Miskulin, A. A. Martin, R. Brown et al., "Predicting 1 year mortality in an outpatient haemodialysis population: A comparison of comorbidity instruments," Nephrology Dialysis Transplantation, vol. 19, no. 2, pp. 413-420, 2004.

[16] J. Liu, Z. Huang, D. T. Gilbertson, R. N. Foley, and A. J. Collins, "An improved comorbidity index for outcome analyses among dialysis patients," Kidney International, vol. 77, no. 2, pp. 141-151, 2010.

[17] S. K. Rigler, J. B. Wetmore, J. D. Mahnken, L. Dong, E. F. Ellerbeck, and T. I. Shireman, "Impact of a modified data capture period on Liu comorbidity index scores in Medicare enrollees initiating chronic dialysis," BMC Nephrology, vol. 14, no. 1, article no. 51, 2013.

[18] W.-C. Kan, J.-J. Wang, S.-Y. Wang et al., "The New Comorbidity Index for Predicting Survival in Elderly Dialysis Patients: A Long-Term Population-Based Study," PLoS ONE, vol. 8, no. 8, Article ID e68748, 2013.

[19] E. L. Knight, N. Ofsthun, M. Teng, J. M. Lazarus, and G. C. Curhan, "The association between mental health, physical function, and hemodialysis mortality," Kidney International, vol. 63, no. 5, pp. 1843-1851, 2003.

[20] S. Hatakeyama, H. Murasawa, I. Hamano et al., "Prognosis of elderly Japanese patients aged $\geq 80$ Years undergoing hemodialysis," The Scientific World Journal, vol. 2013, Article ID 693514, 7 pages, 2013.

[21] M. Thamer, J. S. Kaufman, Y. Zhang, Q. Zhang, D. J. Cotter, and H. Bang, "Predicting early death among elderly dialysis patients: Development and validation of a risk score to assist shared decision making for dialysis initiation," American Journal of Kidney Diseases, vol. 66, no. 6, pp. 1024-1032, 2015.

[22] S. M. Chandna, M. Da Silva-Gane, C. Marshall, P. Warwicker, R. N. Greenwood, and K. Farrington, "Survival of elderly patients with stage $5 \mathrm{CKD}$ : Comparison of conservative management and renal replacement therapy," Nephrology Dialysis Transplantation, vol. 26, no. 5, pp. 1608-1614, 2011. 


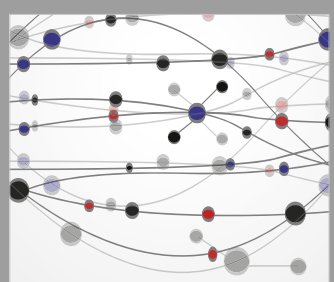

The Scientific World Journal
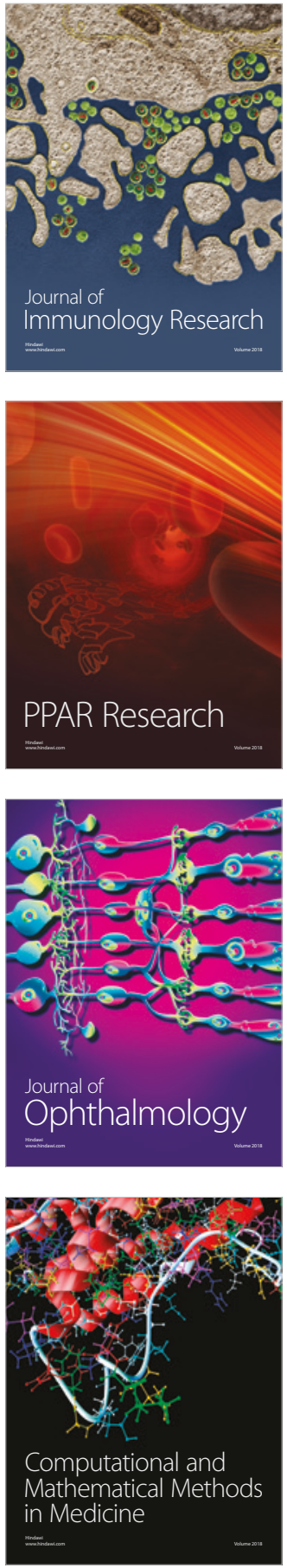

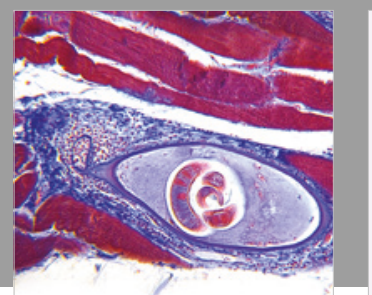

Gastroenterology Research and Practice

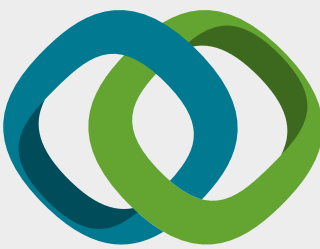

\section{Hindawi}

Submit your manuscripts at

www.hindawi.com
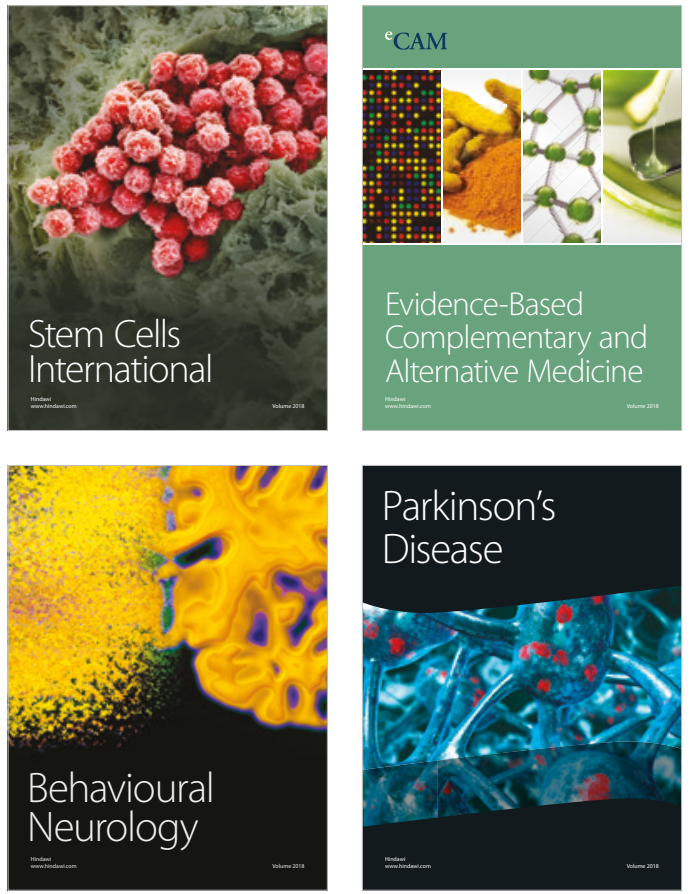

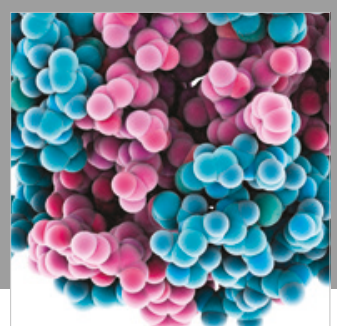

ournal of

Diabetes Research

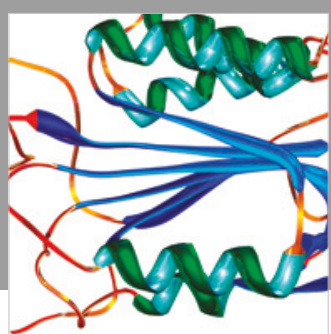

Disease Markers
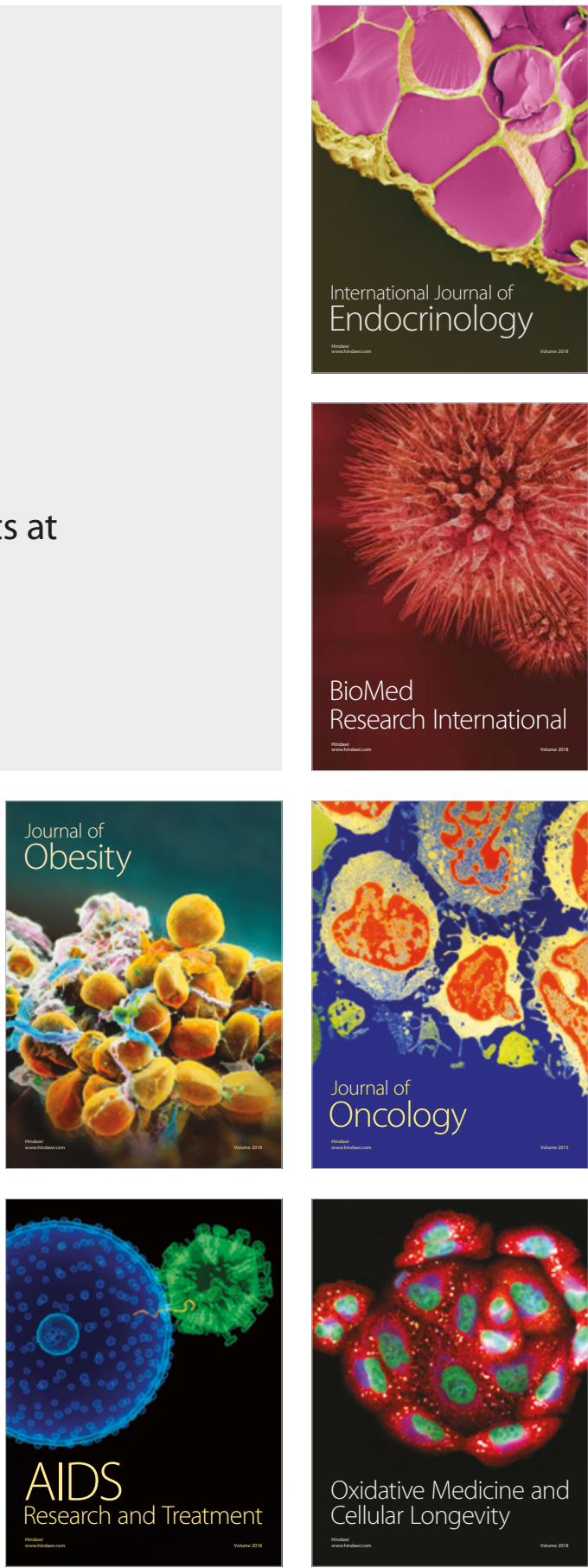